\title{
A Micro-computed Tomographic Assessment of Root Canal Preparation with a Novel Instrument, TRUShape, in Mesial Roots of Mandibular Molars
}

\author{
Peters, Ove A ; Arias, Ana ; Paqué, Frank
}

\begin{abstract}
INTRODUCTION A novel S-shaped rotary file was developed to conform to nonround canal cross sections. However, the instrument should also perform well in small curved canals. This study used micro-computed tomographic scans to test the effects of TRUShape (Dentsply Tulsa Dental Specialties, Tulsa, OK) and a conventional rotary on canal geometry. METHODS Twenty mandibular molars with independent mesial canals were submitted to preoperative micro-computed tomographic scans (20- $\mathrm{m}$ resolution). Canals were randomly allocated to 2 groups using Vortex (Dentsply Tulsa Dental Specialties) and TRUShape for shaping according to the directions for use. Scans were obtained after size 20/.06 and 30/.06; the following outcome variables were calculated: dentin volume, smallest radicular wall thickness, treated canal surface, canal transportation, and accumulated hard tissue debris. The number of preparation errors was tabulated; data were statistically contrasted using repeated measures and factorial analyses of variance. RESULTS The initial canal sizes were similar in both groups. Both instruments promoted preparation with no overt procedural errors. Vortex removed significantly more dentin both at size 20 and $30(\mathrm{P}<.02)$. Significantly $(\mathrm{P}<.02)$ more radicular wall dentin remained toward the furcation in the TRUShape group $(1.02 \pm 0.25 \mathrm{~mm}$ vs $0.94 \pm 0.22 \mathrm{~mm})$. The untreated surface at size 20 was $28.5 \pm 13.9$ and $19.4 \pm 8.9(\mathrm{P}<.05)$, and it was $15.1 \pm 8.5$ and $11.3 \pm 4.9(\mathrm{P}>$ $.05)$ at size 30 for TRUShape and Vortex, respectively. Canal transportation at size 30 varied between $85 \pm 57 \mathrm{~m}$ and $179 \pm 65 \mathrm{~m}$; the overall transportation scores were significantly lower for TRUShape (P $<.05)$. CONCLUSIONS TRUShape provided conservation of dentin by limiting dentin removal and in the absence of substantial canal transportation. In the present study, the use of TRUShape in the mesial canals of mandibular molars did not result in decreased amounts of unprepared canal surface.
\end{abstract}

DOI: https://doi.org/10.1016/j.joen.2015.06.007

Posted at the Zurich Open Repository and Archive, University of Zurich ZORA URL: https://doi.org/10.5167/uzh-121176

Journal Article

Accepted Version

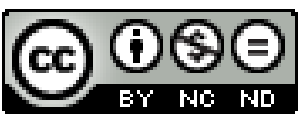

The following work is licensed under a Creative Commons: Attribution-NonCommercial-NoDerivatives 4.0 International (CC BY-NC-ND 4.0) License.

Originally published at:

Peters, Ove A; Arias, Ana; Paqué, Frank (2015). A Micro-computed Tomographic Assessment of Root Canal Preparation with a Novel Instrument, TRUShape, in Mesial Roots of Mandibular Molars. Journal 
of Endodontics, 41(9):1545-1550.

DOI: https://doi.org/10.1016/j.joen.2015.06.007 


\section{Elsevier Editorial System(tm) for Journal of Endodontics}

Manuscript Draft

Manuscript Number: JOE 15-340R1

Title: A micro computed-tomography assessment of root canal preparation with a novel instrument, TRUShape, in mesial roots of mandibular molars

Article Type: Basic Research - Technology

Corresponding Author: Dr. Ove A Peters, DMD, MS, PhD

Corresponding Author's Institution: University of the Pacific, Arthur A. Dugoni School of Dentistry

First Author: Ove A Peters, DMD, MS, PhD

Order of Authors: Ove A Peters, DMD, MS, PhD; Ana Arias, DDS PhD; Frank Paqué, DMD MSc

Manuscript Region of Origin: North America

Abstract: Introduction: A novel S-shaped rotary file was developed to conform to non-round canal cross-sections. However, the instrument should also perform well in small curved canals. This study used microCT scans to test the effects of TRUShape and a conventional rotary on canal geometry. Methods: Twenty mandibular molars with independent mesial canals were submitted to preoperative microCT scans $(20 \mu \mathrm{m}$ resolution). Canals were randomly allocated to two groups, using Vortex and TRUShape (both Dentsply Tulsa Dental) for shaping according to the directions for use. Scans were obtained after size 20/.06 and 30/.06; outcome variables were removed dentin volume, smallest radicular wall thickness, treated canal surface and canals transportation as well as accumulated hard tissue debris. Numbers of preparation errors were tabulated; data was statistically contrasted using repeated measures and factorial ANOVAs.

Results: Initial canal sizes were similar in both groups. Both instruments promoted preparation with no overt procedural errors. Vortex removed significantly more dentin both at size \#20 and \#30 $(\mathrm{p}<0.02)$. Significantly $(\mathrm{p}<0.02)$ more radicular wall dentin remained towards the furcation in the TRUShape group $(1.02 \pm 0.25 \mathrm{~mm}$ vs. $0.94 \pm 0.22 \mathrm{~mm})$. Untreated surface at size \#20 was $28.5 \pm 13.9$ and $19.4 \pm 8.9(\mathrm{p}<0.05)$ and it was $15.1 \pm 8.5$ vs. $11.3 \pm 4.9(\mathrm{p}>0.05)$ at size \#30 for TRUShape and Vortex, respectively. Canal transportation at size \#30 varied between $85 \pm 57 \mu \mathrm{m}$ and $179 \pm 65 \mu \mathrm{m}$; overall transportation scores were significantly lower for TRUShape $(\mathrm{p}<0.05)$. Conclusions: TRUShape provided conservation of dentin by limiting dentin removal and in the absence of substantial canal transportation. In the present study the use of TRUShape in mesial canals of mandibular molars did not result in decreased amounts of unprepared canalsurface. 


\section{A micro computed-tomography assessment of root canal preparation with a novel} instrument, TRUShape, in mesial roots of mandibular molars

Ove A. Peters (DMD MS PhD) ${ }^{1}$

Ana Arias (DDS PhD) ${ }^{1}$

Frank Paqué (DMD MSc) $)^{2}$

1 University of the Pacific, Arthur A. Dugoni School of Dentistry, Department of Endodontics, San Francisco USA

2 University of Zurich Dental School, Zurich, Switzerland

Corresponding author:

Dr. Ove Peters

University of the Pacific, Arthur A. Dugoni School of Dentistry

$1555^{\text {th }} \mathrm{St}$

San Francisco CA94103

USA

Phone +4153517117

e-mail opeters@pacific.edu

Key words: dentin preservation, micro computed tomography, canal transportation, untreated surface Acknowledgment: The authors report that a financial affiliation exists for this paper. 


\section{Highlights}

- A novel rotary instrument, TRUShape, was designed to preserve coronal dentin and to conform to the initial root canal anatomy better than conventional fixed taper rotaries.

- This microCT-based study used mesial canals in mandibular molars as specimens and assesses dentin removal, canal transportation and instrumented surfaceusing well-established procedures.

- Preparation was done with virtually no canal preparation errors and with less coronal dentin removal compared to a fixed-taper rotary instrument.

- The amount of prepared surface was high and similar under the present conditions. 


\begin{abstract}
Introduction: A novel S-shaped rotary file was developed to conform to non-round canal crosssections. However, the instrument should also perform well in small curved canals. This study used microCT scans to test the effects of TRUShape and a conventional rotary on canal geometry.
\end{abstract}

Methods: Twenty mandibular molars with independent mesial canals were submitted to preoperative microCT scans $(20 \mu \mathrm{m}$ resolution). Canals were randomly allocated to two groups, using Vortex and TRUShape (both Dentsply Tulsa Dental) for shaping according to the directions for use. Scans were obtained after size 20/.06 and 30/.06; outcome variables were removed dentin volume, smallest radicular wall thickness, treated canal surface and canals transportation as well as accumulated hard tissue debris. Numbers of preparation errors were tabulated; data was statistically contrasted using repeated measures and factorial ANOVAs.

Results: Initial canal sizes were similar in both groups. Both instruments promoted preparation with no overt procedural errors. Vortex removed significantly more dentin both at size \#20 and \#30 $(\mathrm{p}<0.02)$. Significantly $(\mathrm{p}<0.02)$ more radicular wall dentin remained towards the furcation in the TRUShape group $(1.02 \pm 0.25 \mathrm{~mm}$ vs. $0.94 \pm 0.22 \mathrm{~mm})$. Untreated surface at size \#20 was $28.5 \pm 13.9$ and $19.4 \pm 8.9(\mathrm{p}<0.05)$ and it was $15.1 \pm 8.5$ vs. $11.3 \pm 4.9(\mathrm{p}>0.05)$ at size $\# 30$ for TRUShape and Vortex, respectively. Canal transportation at size \#30 varied between $85 \pm 57 \mu \mathrm{m}$ and $179 \pm 65 \mu \mathrm{m}$; overall transportation scores were significantly lower for TRUShape $(\mathrm{p}<0.05)$. Conclusions: TRUShape provided conservation of dentin by limiting dentin removal and in the absence of substantial canal transportation. In the present study the use of TRUShape in mesial canals of mandibular molars did not result in decreased amounts of unprepared canal surface. 


\section{Introduction}

The purpose of root canal preparation in the context of endodontic therapy is to (i) shape the canals to an adequate geometry and (ii) clean the canal system by promoting access for disinfection solutions; this strategy has been termed chemomechanical canal preparation (1). Importantly, mechanical canal preparation supports disinfection via disturbing biofilms that adhere to canal surfaces (2).

However, root canal preparation should be done with little or no detriment to the outcome of the treatment. Shaping errors such as zipping or perforation are associated with inferior outcomes (3). Many current preparation techniques, including the use of engine-driven nickel-titanium (NiTi) instruments, promote adequate canal shapes (4). Although rotary systems do prepare many canals without major procedural errors, they do not completely address canal types with non-round cross sections. Typically radicular walls of such canals will be incompletely prepared and buccal and lingual extensions uncleaned (5)

Another issue that has received recent attention is the amount of removed dentin, as it may relate to increased susceptibility to fracture (6).

Current suggestions for instrument sequences for canal preparation recommend the creation of straight-line access into the coronal root canal third (7); this step is felt to provide advantages, such as early access for disinfecting irrigants and the ability of rotary instruments to reach deeper canal portions without coronal interferences. However, achieving straight-line access may also result in undue dentin removal and thinning of radicular walls towards the respective danger zone (8).

These considerations resulted in the development of a novel heat-treated nickel-titanium root canal preparation instrument, TRUShape (Dentsply Tulsa Dental Specialties, Tulsa OK) (see insert in Fig. 1). The heat treatment is applied to after flutes are ground into blanks from 
commercially available nickel titanium to shape-set a file into characteristic bends (9). The commercialized set includes instruments with tip sizes of $\# 20, \# 25, \# 30$ and $\# 40$; there is a scurve and a taper of 0.06 in the apical $2 \mathrm{~mm}$, however due to the specific shape the overall taper of the instrument is variable and hence is denoted as $/ .06 \mathrm{v}$. The maximum fluted diameter for all sizes is limited to $0.80 \mathrm{~mm}$ along with a regressive taper; all instruments have the same symmetrical triangular cross-section.

There is currently no data available on canal preparation quality following TRUShape instruments. Therefore the aim of this micro-computed tomography-based study in mesial root of mandibular molars was to generate such a data set using previously established protocols $(10$, 11).

\section{Materials and Methods}

Selection of teeth

From teeth that had been extracted for reasons unrelated to the current study, 20 human mandibular molars of similar corono-apical sizes were collected and stored in $0.1 \%$ thymol solution at $4^{\circ} \mathrm{C}$ until further use. A power analysis for a basic variable of interest, canal volume, had suggested that for $n=20$ per group the study should have $87 \%$ power to detect a difference in removed dentin volumes of $0.5 \mathrm{~mm}^{3}$ with $\alpha=0.05$. This assumption was based on similar experiments with typical volume gains for mesial canals of mandibular molars of $\sim 3 \pm 0.5 \mathrm{~mm}^{3}$ when prepared to a tapered canal and an apical size \#30 (Peters \& Paqué, unpublished data). Teeth were mounted on SEM stubs and scanned in a desktop MCT unit at an isotropic resolution of $20 \mu \mathrm{m}$ ( $\mu \mathrm{CT} 40$, Scanco Medical, Brüttisellen, Switzerland) using previously established methods $(10,11)$. Care was taken to specifically select teeth with two separate apical foramina for each of the mesial root canals. Using a web-based algorithm (www.random.org) a total of 40 
mesial root canals were randomly allocated to each of the two employed shaping instruments, Vortex or the TRUShape prototype (both Dentsply Tulsa Dental Specialties). Care was taken to assign the two techniques in equal proportions to mesiobuccal and mesiolingual canals; each tooth received canal preparation of one mesial canal with each technique. Moreover, preoperative canal volumes and curvatures were determined from MCT scans as described before $(10,12)$ and were found to be statistically similar.

Teeth were then accessed using high-speed diamond burs and patency of the coronal canal confirmed. Canal shaping was done by one operator with $20+$ years of experience with nickel titanium rotaries (O. P.), according to the manufacturer's guidelines. Prior to shaping with Vortex, orifices were enlarged with the $\# 20 / .08$ instrument up to a maximum insertion depth of 3mm. Subsequently both mesial canal lengths and patency were determined with size \#10 K-files (Lexicon, Dentsply Tulsa Dental Specialties) lubricated with ProLube (Dentsply Tulsa Dental Specialties) and digital radiographs were exposed. Working lengths (WLs) were set $0.5 \mathrm{~mm}$ shorter than the radiographic apex. Finally a glide path was then prepared for both groups with Pathfiles 013 and 016 (Dentsply Maillefer, Ballaigues, Switzerland).

\section{Root canal instrumentation with Vortex (group 1)}

Using an electric motor and presets at $500 \mathrm{rpm}$ and $3 \mathrm{Ncm}$, rotaries were used in the following initial sequence: size \#30 /.04 to midroot, \#25 /.04 to 2/3 of WL, \#20 /.04 to WL, 20 /.06 to WL. After an intermediate MCT scan, canals were further enlarged using \#25.06 and \#30 /.06 to WL.

\section{Root canal instrumentation with TRUShape (group 2)}

Using an electric motor and presets at $300 \mathrm{rpm}$ and $3 \mathrm{Ncm}$, rotaries were used in the following manner: size \#20 /.06v to WL. After an intermediate MCT scan, canals were further enlarged 
using \#30/.06v to WL. TRUShape instruments were advanced to midroot in $2-5 \mathrm{~mm}$ in-and-out motions to shape and then in further $2-3 \mathrm{~mm}$ amplitude gentle in-and-out motions towards working length. Brushing was not utilized for TRUShape nor Vortex in accordance with either Directions for Use.

After each instrument insertion, $1 \mathrm{~mL} 6 \% \mathrm{NaOCl}$ was applied with a $30 \mathrm{~g}$ ProRinse needle (Dentsply Tulsa Dental Specialties) placed as deep into the canals as possible without binding.

After shaping a final flush of $1 \mathrm{~mL}, 17 \%$ EDTA was applied for $1 \mathrm{~min}$.

The operator was not allowed to see the virtual models of reconstructed teeth before preparing the root canals and during the course of the treatment. This was done so as to avoid bias by an attempt to manually direct the preparation instrument into any potentially un-instrumented area. Preparation was done according to the manufacturer's guidelines with Vortex; directions for use were established and affirmed during the course of preliminary trials for TRUShape.

\section{Evaluation}

Virtual root canal models were reconstructed based on MCT scans and superimposed with a precision of better than 1 voxel using VGStudio 2.2 (VolumeGraphics, Heidelberg, Germany) and commercial software (IPL, Scanco Medical). Precise repositioning of pre- and various postpreparation images was ensured by a combination of a custom-made mounting device and a software-controlled iterative superimposition algorithm (10-12); the resulting color-coded root canal models (green indicates preoperative, red postoperative canal surfaces) enabled quantitative comparison of the matched root canals before and after shaping.

First, virtual canal models were carefully inspected and scored for obvious forms of canal preparation errors such as the presence of an instrument fragment or strip perforation. Then, from individual canal models, canal volumes up to the level of the cemento-enamel junction (CEJ) as 
well as in the apical $4 \mathrm{~mm}$ were determined using custom-made software (IPL, Scanco Medical) as described previously (10). Increases in volume and surface area (data not shown) were calculated by subtracting the scores for the treated canals from those recorded for the untreated counterparts. The distance from canal wall to the furcation was measured in matched crosssections before and after shaping. Matched 3D models of the canals, before and after preparation, were examined to evaluate the amount of un-instrumented canal wall area. This parameter was expressed as a percentage of the number of static voxel surface to the total number of surface voxels. Using superimposed virtual canal models, the smallest distance to the furcation area, usually located in the coronal or middle root canal third was determined for both unprepared canals and canals prepared to apical sizes $\# 20$ and \#30.

Canal transportation was determined as described previously in detail $(10,12)$. In brief, "centers of gravity" were calculated for each slice and connected along the z-axis with a fitted line. Mean transportation scores were then calculated by comparing the centers of gravity before and after treatment for the apical, mid and coronal thirds of the canals.

Accumulated debris was calculated as described previously (13); in brief, from superimposed models, volumes were determined of canal spaces that were visible in the preoperative scans but not in postoperative images.

\section{Statistical analysis}

Voxel volume in this data set was $8 \times 10^{-6} \mathrm{~mm}^{3}$ and such data is reported as means \pm S.D., rounded to the nearest $1 / 100 \mathrm{~mm}^{3}$. All data was tabulated for further analysis; prepared canal surface area is presented as percentages relative to preoperative canal surface areas and canal transportation is reported in $\mu \mathrm{m}$ distance. 
Since normality assumptions were verified in the data set, means were compared using one- and two-way ANOVAs with Scheffé tests for post-hoc comparison; the level of statistical significance was set at $\alpha=0.05$.

\section{Results}

Overall, both instruments appeared to prepare narrow and curved canals well and without obvious preparation errors (Figs. 1B, C). No instrument fractures occurred in either group while increasing the canal volumes by removing dentin gradually in two preparation steps (Table 1). TRUShape removed about $36 \%$ less dentin in mesial roots prepared to size \#20 and 26\% less dentin prepared to size \#30. This difference was significant at both preparation steps $(\mathrm{p}<0.02)$.

Initial radicular wall thickness was similar for both groups (Table 1) with the thinnest sections always present in the coronal one third at the transition to the middle third. Canal preparation resulted in progressive removal of wall dentin with the two preparation steps. The amount of dentin remaining towards the furcation was significantly higher with TRUShape both at size \#20 and \#30 ( $<0.02$, Table 1 and Fig. 1D).

Both instruments were associated with various degrees of measurable canal transportation, which was in general directed towards the furcation in the coronal root canal half and to outside of the curvature in the apical canal portion. Transportation scores were averaged over root canal thirds and ranged from $53 \pm 19 \mu \mathrm{m}$ to $179 \pm 65 \mu \mathrm{m}$. Absolute canal transportation was significantly different $(\mathrm{P}<0.05)$ at each step, except in the apical third when shaping to size \#20 (Table 2). Canal transportation was typically below $150 \mu \mathrm{m}$, with the exception of the coronal canal third; in this segment 10 and 12 cases for Vortex and 3 and 5 cases for TRUShape had transportation in excess of $150 \mu \mathrm{m}$ when shaped to sizes \#20 and \#30, respectively.

Based on semi-automated superimposition of the different data sets canal wall surface changes 
were assessed. Specifically, the amount of untreated canal area was determined by counting the number of static voxels; the data are presented in Table 3 separately for the canal overall and the apical $4 \mathrm{~mm}$. Scores are similar except for the first preparation step, when the full canal was considered.

Finally, the amount of remaining hard tissue debris was determined; it ranged from $0.96 \pm 0.77$ to $2.15 \pm 1.81 \%$ of the respective overall volumes. There were no significant differences between the two shaping techniques, however, enlargement to size \#30 resulted in less hard tissue debris in mesial canals $(\mathrm{p}<0.05)$.

\section{Discussion}

This in vitro study on mandibular molars was designed as an initial assessment of a novel canal preparation instrument, TRUShape compared to an established fixed-taper instrument, Vortex. Overall both instrument systems performed well. This assessment takes into account the fact that a single experienced clinician shaped the canals with both rotaries. In small and curved canals in mesial roots of mandibular molars it was found that this new rotary instrument shaped canals with no obvious preparation errors. Compared to an established fixed-taper system, TRUShape removed less bulk dentin and left more dentin wall. This difference is significant and amounts to about $36 \%$ and $26 \%$ less dentin removed, when preparing to apical sizes $\# 20$ and $\# 30$, respectively. Overall canal shapes were without visible preparation errors; canal transportation was typically low and prepared canal surfaces similar and high.

This study used an established design (see Supplemental Table S1), based on micro computed tomography (MCT). The selection of mesial roots of mandibular molars permitted preparation of canals of similar lengths and dentin hardness with both. Limitations of such a study design are the typically low number of samples ( $\mathrm{n}=20$ here). In consequence an impact of canal anatomy on the 
outcome cannot be excluded (14). There was a single operator with $>20$ years experience in rotary root canal preparation; the operator was blinded in regards to the preoperative MCT scans and the canal allocation was strictly random. The evaluation was done on coded specimens, reducing the possibility of bias.

Over the last decade MCT has developed into a frequently used tool for shaping assessment, with pertinent studies listed in Supplemental Table S1. For all assessed variables, comparison data is available, for example the reported amount of removed dentin volume varied from $0.5-3.5 \mathrm{~mm}^{3}$ $(15,16)$, with the majority of the studies showing values in the range of $1-2.5 \mathrm{~mm}^{3}(17-23)$. These sizeable differences may be explained by differences in initial canal anatomy and selecting the volume of interest (VOI), as much as the preparation technique itself. A study with a similar VOI definition found reduction in dentin volume of $1.7-2.6 \mathrm{~mm}^{3}$ when shaping to an apical size $\# 25$ with an /.08 taper (24). In the present study the smaller maximum fluted diameter of TRUShape $(0.80 \mathrm{~mm})$ resulted in less dentin removed compared to a fixed /.06 taper with Vortex.

There are some reports on radicular wall thicknesses that confirm the present findings of about $1 \mathrm{~mm}$ dentin pre-operatively towards the so-called danger zone $(25,26)$. The amount of remaining dentin after shaping depends on canal transportation and this number in turn depends on canal curvature. Therefore it is difficult to directly compare the present results with data from other studies $(15,25)$; however, between the two instruments tested under the present conditions, TRUShape resulted in more dentin remaining towards the furcation. It is a matter of debate if the amount of preserved structure will translate into enhance clinical outcomes; however, in the absence of a clinical study directly testing this hypothesis it seems reasonable to consider that fracture is a frequently cited reason for extraction (27).

The amount of unprepared canal surface has been the focus of several studies in mesial root canals of mandibular molars and has found to vary greatly, from about $16 \%$ to $48 \%(16,17,20$, 
$22,24,28)$. The scores found in the current study suggest that shaping to size $\# 20$ with neither instrument is sufficient to attain a high portion of instrumented surface in an attempt to increase the antimicrobial efficacy of root canal preparation (14). However, at size \#30, 85\% or more of mesial canal surface in mandibular molars was instrumented in the present study.

Another instrument, the self-adjusting file (SAF, Redent-Nova, Ranaa, Israel) has been designed to conform to non-round canal cross-sections. However, the use of the SAF in a study by Siqueira et al. (28) resulted in larger prepared surface compared to the rotary instruments included; both rotaries in the present study achieved higher amounts of prepared surface. Moreover, these authors (28) could not confirm a correlation between prepared canal surface and reduction in microbial burden in typically small and round cross-sections of mesial canals in mandibular molars.

It has been demonstrated that severe canal transportation, e.g., strip perforation, is related to inferior outcomes (3); hence numerical comparison of canal transportation is frequently done in the assessment of preparation quality. A variety of methods have been used in MCT-based studies $(20,23,29-31)$, for example vector-based and trigonometry-based numbers. Since these assessments provide partial scores, including the direction of transportation, it is again difficult to directly compare the results of the present study.

Using methods similar to those employed in this study, ProTaper Universal, ProTaper Next and WaveOne (all Dentsply Tulsa Dental), when shaping to an apical size \#25, were associated with similar or greater transportation (see Supplemental Table S1) compared to TRUShape in canals shaped an apical size \#30; Vortex on the other hand was associated with overall larger transportation scores. It has been held that a "displacement of center of gravity of up to about 150 $\mu \mathrm{m}$ can be regarded as acceptable" (32); in the middle and apical thirds this criterion was fulfilled in more than $90 \%$ of the canals. 
Expected outcomes of root canal treatment must include the healing of apical periodontitis, if present preoperatively. However, current findings based on large patient cohorts look into retention as a potential outcome of endodontic treatment $(33,34)$. Recently it was confirmed that more teeth had to be removed after root canal treatment due to restorative issues, rather than due to persistent or recurrent apical pathosis (27). Therefore the challenge for future root canal preparation techniques is to provide enhanced antimicrobial efficacy and retain as much restorable tooth as possible. More research beyond this initial assessment of TRUShape is needed to suggest that this is attainable.

Within the limitations of the present in vitro study the following conclusions may be reached. Both instruments tested are suitable for the preparation of mesial canals of mandibular molars. TRUShape resulted in conservation of dentin by limited dentin removal and with minimal canal transportation; however, in small mesial canals in mandibular molars described in the present study the use of TRUShape did not result in increased amounts of treated canal surface.

\section{Conflict of interest disclosure:}

This project was financially supported by Dentsply Tulsa Dental. Parts of the work described have been presented at the Annual Meeting of the American Association of Endodontists in Seattle, WA. Dr. Ove Peters serves as a consultant to Dentsply Tulsa Dental. 


\section{Legends}

Figure 1: Three-dimensional (three left panels) and cross-sectional appearance of a mandibular molar, with the canal prepared with TRUShape seen right and Vortex shapes shown to left. Images in A show un-instrumented mesial canals, while B and C show the appearance after shaping to sizes \#20 and 30, respectively. Panel shows cross-sections in the coronal, middle and apical third, with the respective canal preparation indicated by color.

Note: Length bar is $1 \mathrm{~mm}$. Insert at bottom is a schematic drawing of the TRUShape rotary size \#20.06v. 


\section{References}

1. Stewart GG. The importance of chemomechanical preparation of the root canal. Oral Surg Oral Med Oral Pathol 1955;8:993-7.

2. Svensäter G, Bergenholtz G. Biofilms in endodontic infections. Endod Topics 2004:27-

36.

3. Pettiette MT, Delano EO, Trope M. Evaluation of success rate of endodontic treatment performed by students with stainless-steel K-files and nickel-titanium hand files. J Endod $2001 ; 27: 124-7$.

4. Cheung GS, Liu CS. A retrospective study of endodontic treatment outcome between nickel-titanium rotary and stainless steel hand filing techniques. J Endod 2009;35:938-43.

5. Wu MK, Wesselink PR. A primary observation on the preparation and obturation of oval canals. Int Endod J 2001;34:137-41.

6. Zelic K, Vukicevic A, Jovicic G, Aleksandrovic S, Filipovic N, Djuric M. Mechanical weakening of devitalized teeth: three-dimensional Finite Element Analysis and prediction of tooth fracture. Int Endod J 2014:epub ahead of print.

7. Peters OA, Peters CI. Preparation of root canal systems. In: Hargreaves KM, Cohen S, editors. Pathways of the Pulp. 10th ed. St. Louis MO: Elsevier; 2010. p. 283-348.

8. Kuttler S, McLean A, Dorn S, Fischzang A. The impact of post space preparation with Gates-Glidden drills on residual dentin thickness in distal roots of mandibular molars. J Am Dent Assoc 2004;135:903-9.

9. Ammon D, Shotton V, Gao Y, Maxwell R, Inventors; Dentsply Inc, York (PA), assignee. Endodontic instruments and methods of manufacturing thereof. US 8,916,009 B2, 2014.

10. Peters OA, Schönenberger K, Laib A. Effects of four Ni-Ti preparation techniques on root canal geometry assessed by micro computed tomography. Int Endod J 2001;34:221-30. 
11. Paqué F, Ganahl D, Peters OA. Effects of root canal preparation on apical geometry assessed by micro-computed tomography. J Endod 2009;35:1056-9.

12. Peters OA, Laib A, Ruegsegger P, Barbakow F. Three-dimensional analysis of root canal geometry by high-resolution computed tomography. J Dent Res 2000;79:1405-9.

13. Paqué F, Boessler C, Zehnder M. Accumulated hard tissue debris levels in mesial roots of mandibular molars after sequential irrigation steps. Int Endod J 2011;44:148-53.

14. Peters OA, Paqué F. Current developments in rotary root canal instrument technology and clinical use: a review. Quintessence Int 2010;41:479-88.

15. Peru M, Peru C, Mannocci F, Sherriff M, Buchanan LS, Pitt Ford TR. Hand and nickeltitanium root canal instrumentation performed by dental students: a micro-computed tomographic study. Eur J Dent Educ 2006;10:52-9.

16. Markvart M, Darvann TA, Larsen P, Dalstra M, Kreiborg S, Bjørndal L. Micro-CT analyses of apical enlargement and molar root canal complexity. Int Endod J 2012;45:273-81.

17. Yang G, Yuan G, Yun X, Zhou X, Liu B, Wu H. Effects of two nickel-titanium instrument systems, Mtwo versus ProTaper universal, on root canal geometry assessed by microcomputed tomography. J Endod 2011;37:1412-6.

18. Moore J, Fitz-Walter P, Parashos P. A micro-computed tomographic evaluation of apical root canal preparation using three instrumentation techniques. Int Endod J 2009;42:1057-64.

19. You SY, Kim HC, Bae KS, Baek SH, Kum KY, Lee W. Shaping ability of reciprocating motion in curved root canals: a comparative study with micro-computed tomography. J Endod 2011;37:1296-300.

20. Zhao D, Shen Y, Peng B, Haapasalo M. Root canal preparation of mandibular molars with 3 nickel-titanium rotary instruments: a micro-computed tomographic study. J Endod 2014;40:1860-4. 
21. Baek SH, Yoo HM, Park DS, Oh TS, Kum KY, Chang SW. Comparison of the shaping abilities of three nickel-titanium instrumentation systems using micro-CT. J Dent Scie 2014;9:111-7.

22. Gergi R, Osta N, Bourbouze G, Zgheib C, Arbab-Chirani R, Naaman A. Effects of three nickel titanium instrument systems on root canal geometry assessed by micro-computed tomography. Int Endod J 2015;48:162-70.

23. Kim H-C, Hwang Y-J, Jung D-W, You S-Y, Kim H-C, Lee W. Micro-computed tomography and scanning electron microscopy comparisons of two nickel-titanium rotary root canal instruments used with reciprocating motion. Scanning 2013;35:112-8.

24. Paqué F, Zehnder M, De-Deus G. Microtomography-based comparison of reciprocating single-file F2 ProTaper technique versus rotary full sequence. J Endod 2011;37:1394-7.

25. Sant'Anna Junior A, Cavenago BC, Ordinola-Zapata R, De-Deus G, Bramante CM, Duarte MA. The effect of larger apical preparations in the danger zone of lower molars prepared using the Mtwo and Reciproc systems. J Endod 2014;40:1855-9.

26. Harris SP, Bowles WR, Fok A, McClanahan SB. An anatomic investigation of the mandibular first molar using micro-computed tomography. J Endod 2013;39:1374-8.

27. Landys Boren D, Jonasson P, Kvist T. Long-term survival of endodontically treated teeth at a public dental specialist clinic. J Endod 2015;41:176-81.

28. Siqueira Jr. JF, Alves FR, Versiani MA, Rôças IN, Almeida BM, Neves MA, et al. Correlative bacteriologic and micro-computed tomographic analysis of mandibular molar mesial canals prepared by Self-Adjusting File, Reciproc, and Twisted File systems. J Endod 2013;39:1044-50. 
29. Yamamura B, Cox TC, Heddaya B, Flake NM, Johnson JD, Paranjpe A. Comparing canal transportation and centering ability of endosequence and vortex rotary files by using microcomputed tomography. J Endod 2012;38:1121-5.

30. Vallaeys K, Chevalier V, Arbab-Chirani R. Comparative analysis of canal transportation and centring ability of three Ni-Ti rotary endodontic systems: Protaper, MTwo and Revo-S, assessed by micro-computed tomography. Odontology 2014:epub ahead of print.

31. Marceliano-Alves MF, Sousa-Neto MD, Fidel SR, Steier L, Robinson JP, Pecora JD, et al. Shaping ability of single-file reciprocating and heat-treated multifile rotary systems: a micro-CT study. Int Endod J 2014:epub ahead of print.

32. Peters OA. Current challenges and concepts in the preparation of root canal systems: a review. J Endod 2004;30:559-67.

33. Salehrabi R, Rotstein I. Endodontic treatment outcomes in a large patient population in the USA: an epidemiological study. J Endod 2004;30:846-50.

34. Fonzar F, Fonzar A, Buttolo P, Worthington HV, Esposito M. The prognosis of root canal therapy: a 10-year retrospective cohort study on 411 patients with 1175 endodontically treated teeth. Eur J Oral Implantol 2009;2:201-8. 


\section{IIck nere to download hıgh resolution ımage}
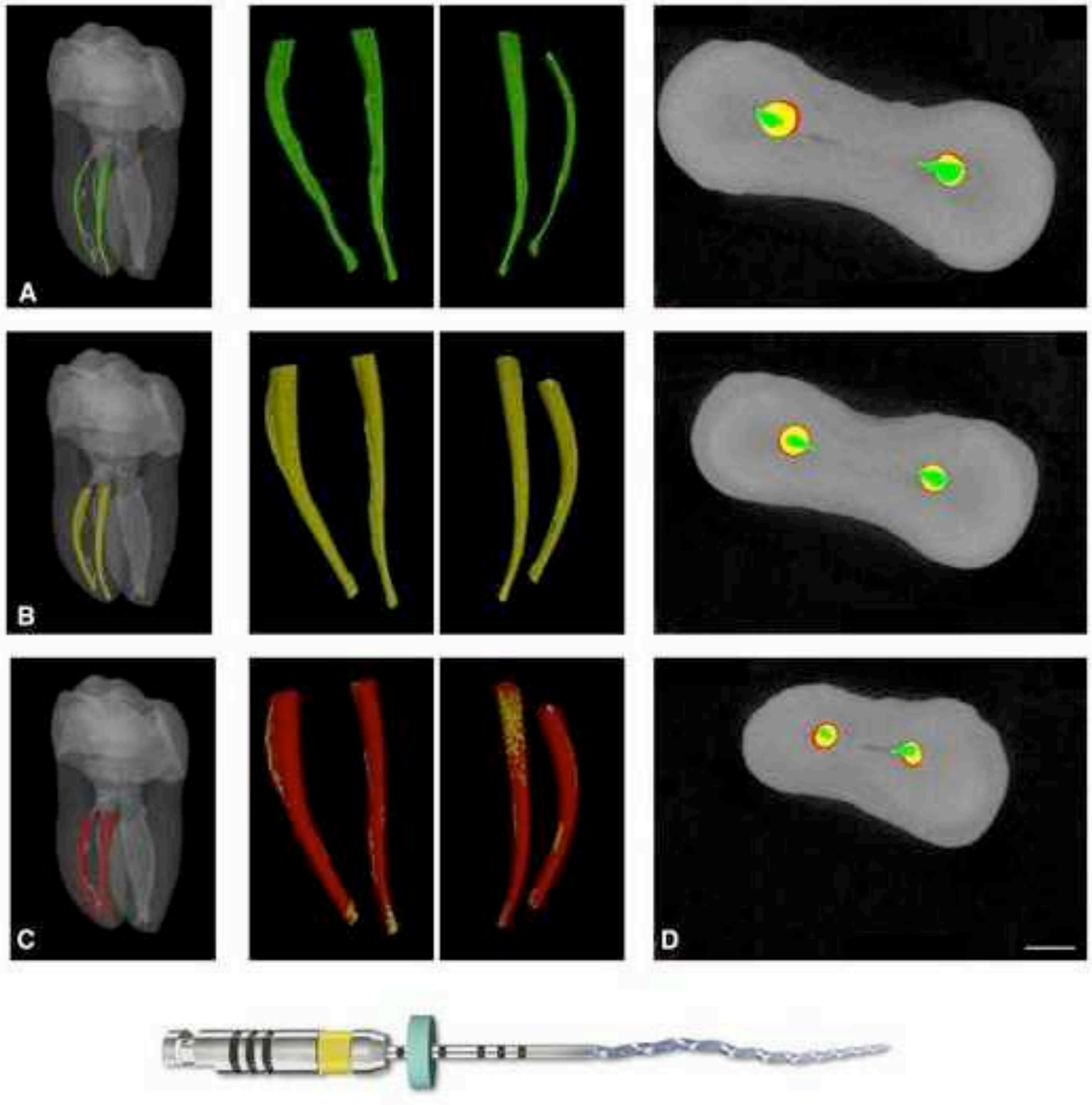
TAB. 1: Shaping outcomes of mesial canals with TRUShape and Vortex ( $n=20$ each). Unprepared canals were statistically similar in size and dentin thickness to furcation $(p>0.05)$. TRUShape resulted in significantly less dentin removed and less encroachment towards the furcation (each $\mathrm{p}<0.02$ ). Canal volumes increased significantly with both instruments from to size \#20 and then again to size \#30, compared to unshaped condition $(\mathrm{p}<0.0001)$. Data points with different superscript letter indicate significant differences.

\begin{tabular}{|c|c|c|c|c|}
\hline & \multicolumn{2}{|c|}{ TRUShape } & \multicolumn{2}{|c|}{ Vortex } \\
\hline Apical Size & $\# 20$ & $\# 30$ & $\# 20$ & $\# 30$ \\
\hline $\begin{array}{l}\text { Dentin Volume } \\
\text { Loss after Shaping } \\
{\left[\mathrm{mm}^{3}\right]}\end{array}$ & $1.34 \pm 0.61^{\mathrm{a}}$ & $2.17 \pm 0.85^{b}$ & $2.10 \pm 0.95^{\mathrm{b}}$ & $2.95 \pm 1.12^{\mathrm{c}}$ \\
\hline $\begin{array}{l}\text { Initial canal } \\
\text { volume } \\
{\left[\mathrm{mm}^{3}\right]}\end{array}$ & \multicolumn{2}{|c|}{$1.41 \pm 0.41$} & \multicolumn{2}{|c|}{$1.29 \pm 0.28$} \\
\hline $\begin{array}{l}\text { Remaining } \\
\text { radicular wall } \\
\text { thickness [mm] }\end{array}$ & $1.09 \pm 0.25^{\mathrm{d}}$ & $1.02 \pm 0.25^{\mathrm{e}}$ & $1.02 \pm 0.22^{\mathrm{d}}$ & $0.94 \pm 0.22^{f}$ \\
\hline $\begin{array}{ll}\text { Initial } & \text { radicular } \\
\text { wall } & \text { thickness } \\
{[\mathrm{mm}]} & \end{array}$ & \multicolumn{2}{|c|}{$1.32 \pm 0.22$} & \multicolumn{2}{|c|}{$1.35 \pm 0.24$} \\
\hline
\end{tabular}


TAB. 2: Canal transportation, expressed as center of mass shift in $\mu \mathrm{m}$, after preparation with TRUShape and Vortex ( $\mathrm{n}=20$ each). TRUShape was associated with overall less canal transportation in mesial canals (ANOVA, $\mathrm{p}<0.05$ ). All pairwise comparisons indicated significant differences $(\mathrm{p}<0.05)$, except for the apical third at size \#20. Data points with different superscript letter indicate significant differences.

\begin{tabular}{|l|l|l|l|l|}
\hline & \multicolumn{2}{|c|}{ TRUShape } & \multicolumn{2}{c|}{ Vortex } \\
\hline Apical Size & \multicolumn{1}{|c|}{$\# 20$} & \multicolumn{1}{c|}{$\# 30$} & \multicolumn{1}{c|}{$\# 30$} \\
\hline Coronal 1/3 & $110 \pm 34^{\mathrm{a}}$ & $133 \pm 37^{\mathrm{c}}$ & $153 \pm 60^{\mathrm{e}}$ & $179 \pm 65^{\mathrm{e}}$ \\
\hline Middle 1/3 & $53 \pm 19^{\mathrm{b}}$ & $71 \pm 28^{\mathrm{d}}$ & $77 \pm 30^{\mathrm{d}}$ & $102 \pm 36^{\mathrm{g}}$ \\
\hline Apical 1/3 & $58 \pm 37^{\mathrm{b}}$ & $85 \pm 57^{\mathrm{d}}$ & $85 \pm 55^{\mathrm{bd}}$ & $112 \pm 66^{\mathrm{g}}$ \\
\hline
\end{tabular}


TAB. 3: Unprepared canal surface after preparation with TRUShape and Vortex in mesial canals $(n=20)$. Both instruments prepared similar amounts of canal surface, except in the first enlargement step and over the full canal length. Data points with different superscript letter indicate significant differences.

\begin{tabular}{|l|c|c|c|c|}
\hline & \multicolumn{2}{|c|}{ TRUShape } & \multicolumn{2}{c|}{ Vortex } \\
\hline Apical Size & \multicolumn{1}{|c|}{$\# 20$} & $\# 30$ & $\# 20$ & \\
\hline $\begin{array}{l}\text { \%Unprepared } \\
\text { surface } \\
\text { (overall) }\end{array}$ & $28.5 \pm 13.9^{\mathrm{a}}$ & $15.1 \pm 8.5^{\mathrm{c}}$ & $19.4 \pm 8.9^{\mathrm{b}}$ & $11.3 \pm 4.9^{\mathrm{c}}$ \\
\hline $\begin{array}{l}\text { \%Unprepared } \\
\text { surface } \\
\text { (apical 4mm) }\end{array}$ & $43.5 \pm 20.3^{\mathrm{e}}$ & $19.4 \pm 11.8^{\mathrm{f}}$ & $34.1 \pm 13.4^{\mathrm{e}}$ & $19.1 \pm 10.2^{\mathrm{f}}$ \\
\hline
\end{tabular}


Instruments tested K-file vs ProTaper vs GT

ProTaper F2, rotary vs. reciprocating

K-file vs ProTaper/Flexmaster hybrid

ProTaper Universal vs Mtwo

ProTaper F2, rotary vs. reciprocating ser reciprocating vs Protaper vs TF rotating

GT/Profile vs Race/Niti K-file

EndoEZE AET vs ProTaper Universal

SAF vs TF vs Reciproc

ProTaper vs WaveOne

Profile vs WaveOne vs Twisted File

MTwo (rot) vs MTwo (recip) vs Reciproc iproc vs WaveOne vs Twisted File Adaptive

Reciproc vs TF vs Hyflex vs WaveOne Ier Universal vs WaveOne vs ProTaper Next

ProTaper F2, rotary vs. reciprocating

ProTaper Universal vs MTwo GT/Profile vs Race/Niti K-file SAF vs TF vs Reciproc

iproc vs WaveOne vs Twisted File Adaptive er Universal vs WaveOne vs ProTaper Next

ProTaper F2, rotary vs. reciprocating

ProTaper Universal vs MTwo ProTaper F2, rotary vs. reciprocating

EndoSequence vs Vortex $30 \quad .04,40.04$ aper reciprocating vs ProTaper and Twisted

File rotating ProTaper vs WaveOne ProTaper vs Safesider vs RaCe Profile vs WaveOne vs Twisted File MTwo (rot) vs MTwo (recip) vs Reciproc :iproc vs WaveOne vs Twisted File Adaptive Jroc vs Twisted File vs Hyflex vs WaveOne WaveOne vs Twisted File Reciproc vs WaveOne vs TF Adaptive

\section{Reference}

Peru 2006 (1)

recalcı

Paque 2011 (2)

same data collection

Moore 2009 (3)

Yang 2011 (4)

You 2011 (5)

Stern 2012 (6)

Markvart 2012 (7)

Moura Netto 2013 (8)

Siqueira 2013 (9)

Kim 2013 (10)

Baek 2013 (11)

report $\mathrm{x}]$

Hwang 2014 (12)

Gergi 2015 (13)

Marceliano-Alves 2014 (14)

Zhao 2014 (15)

Paque 2011 (2)

same data collection

Yang 2011 (4)

Markvart 2012 (7)

Siqueira 2013 (9) Correlative analysis showed no statistically sigr bacterial reduction and the mean percentage increase

Gergi 2015 (13)

Zhao 2014 (15)

Paque 2011 (2)

same data collection and el

Yang 2011 (4)

You 2011 (5)

Yamamura $2012(16)$

Stern 2012 (6)

transportation c

Kim 2013 (10)

Ceyhanli 2013 (17)

Baek 2013 (11)

Hwang 2014 (12)

Gergi 2015 (13)

Marceliano-Alves 2014 (14)

Junaid 2014 (18)

Gergi 2014 (19) 